УДК 316

$10.17213 / 2075-2067-2020-4-31-36$

\title{
СОЦИАЛЬНЫЕ ОСОБЕННОСТИ ЦИФРОВИЗАЦИИ ОБРАЗОВАТЕЛЬНОГО ПРОЦЕССА В ВЫСШЕМ УЧЕБНОМ ЗАВЕДЕНИИ
}

\author{
(C) 2020 г. А. Н. Руденко \\ Ростовский государственный экономический университет (РИНХ), \\ 2. Ростов-на-Дону, Россия
}

Целью исследования является раскрытие основных стратегических особенностей внедрения цифровых образовательных технологий в учебный процесс вуза и параллельно проведение аналитической деятельности, раскрывающей степень влияния данных технологий на изменение социального взаимодействия между обучающиимся и профессорскопреподавательским составом, в том числе в области результатов освоения первыми учебных материалов.

Методологическую базу исследования представляет опыт современных дата-инженеров в образовании, педагогических дизайнеров, педагогов Университета НТИ «20.35».

Результаты исследования. Система высшего образования, подкрепленная на постоянной основе электронной обратной связью от студентов в изифровой образовательной среде, имеет ряд преимущуественных особенностей как для образовательной организаичи, так и для самих обучающихся. Это касается повышения интенсивности и вовлеченности студентов в процесс обучения, объективизации оценочной системы уровня знаний, умений и навыков, оптимизации затраченного времени и др. Разумеется, данная система не лишена недостатков, которые в первую очередь имеют отношение к технической организации ииифрового пространства, непрерывному Интернет-соединению и пользовательскому опьту.

Перспективу исследования составляет дальнейшее соииологическое исследование приобретаемого опыта образовательных организаций в поиске и внедрении новых инструментов циирровых образовательных технологий.

Ключевые слова: циирровизация высшего образования; электронные образовательные технологии; образовательные инструменты; эффективное сочиильное взаимодействие; сочиально-педагогическая деятельность.

\section{SOCIAL FEATURES DIGITALIZATION OF THE EDUCATIONAL PROCESS IN HIGHER EDUCATION INSTITUTIONS}

\section{(C) 2020 A. N. Rudenko}

\section{Rostov State University of Economics (RSUE), Rostov-on-Don, Russia}

The purpose of the study is to reveal the main strategic features of the introduction of digital educational technologies in the educational process of the University and in parallel to conduct analytical activities that reveal the degree of influence of these technologies on the change in social interaction between students and faculty, including in the field of the results of the first learning materials. 
The methodological base of the study is the experience of modern data engineers in education, pedagogical designers, teachers of the NTI «20.35» University.

The results of the study. The system of higher education, supported on a permanent basis by electronic feedback from students in the digital educational environment, has a number of advantages, both for the educational organization and for the students themselves. This applies to increasing the intensity and involvement of students in the learning process, objectifying the assessment system of the level of knowledge, skills, optimization of time spent, etc. Of course, this system is not without its drawbacks, which are primarily related to the technical organization of the digital space, continuous Internet connection and user experience.

The prospect of the study is a further sociological study of the acquired experience of educational organizations in the search and implementation of new tools of digital educational technologies.

Key words: digitalization of higher education; electronic educational technologies; educational tools; effective social interaction; social and pedagogical activity.

Введение. Система обучения, бесспорно, играет ключевую роль в образовании любого уровня. Контактное обучение, без всякого сомнения, обладает достаточно высоким уровнем эффективности и в значительной степени поднимает качественную составляющую образования, но современное информационное общество с его новейшими технологиями и учебными материалами предъявляет новые требования к образованию [1]. На наших глазах в последнее время рождается новый рынок образовательных услуг, кардинально отличающийся от привычного, который складывался столетиями. Ученые прогнозируют появление новой экосистемы высокотехнологичных образовательных услуг [4].

\section{Внедрение цифровых образователь- ных инструментов в учебный процесс.} Во время пандемии образовательные организации преодолели значительные изменения и модификации в структуре своего основного вида деятельности, что в корне изменило набор социальных действий профессорско-преподавательского состава и обучающихся. Как показывают результаты, перевод учебного процесса в электронную информационнообразовательную среду обеспечил довольно значительный рост интенсивности и вовлеченности сторон в среднем в 2,5 раза. Если ранее в контактном режиме непрерывную активность проявляли около 20-30\% испытуемых, учебные занятия выглядели следующим образом.
Лекционное занятие в преобладающем большинстве случаев носило монологический характер. Для закрепления материала и развития логического мышления педагог задавал вопросы в диалоговом режиме, положительно выделенным за правильный ответ на каждый из них мог быть только один обучающийся, кто первым смог воспроизвести точную информацию. Каждого отвечающего слушали все члены потока в порядке живой очереди. Такой подход практически лишает преподавателя понимания уровня освоенности доводимой им информации до каждого присутствующего, тем более затруднительным и затратным по времени является сам процесс персонализации, если речь идет о целом потоке.

Практическое занятие представляло собой выступления трех-пяти студентов, которые изъявляли желание ответить на один вопрос рассматриваемой темы, откровенно говоря, даже не скрывая тот факт, что они заранее договорились с одногруппниками о распределении вопросов, которые они будут готовить. Каким образом мы можем оценить в такой ситуации образовательный результат? Максимальный образовательный результат представляет собой следующий образ - все студенты усвоили все вопросы рассматриваемой темы, получили в полном объеме необходимые умения и навыки. При классическом образовательном подходе максимальный результат представляется недостижимой мечтой. 
Лабораторные занятия обладают наибольшей степенью эффективности, которая складывается из минимального числа присутствующих и индивидуальной работы каждого из них.

Современные педагоги задумались над тем, что возникла острая необходимость совершенствования процесса обучения и повышения эффективности как преподавания, так и полученных результатов обучения, а современное информационное общество может предоставить технологии, с помощью которых возможно было бы реализовать данные стремления.

Внедрение цифровых образовательных технологий предполагает создание цифрового пространства или цифровой образовательной среды, освоить которую далеко не так просто, как учебную аудиторию. Современные студенты с легкостью взаимодействуют в различных социальных средах в интернет-пространстве, чувствуя себя, как «рыба в воде». Обучение с использованием данных технологий повысит интерес, вовлеченность и соответственно уровень образовательного результата [2, 3].

Данное предположение было реализовано в большей степени. Переместившись в цифровую образовательную среду, более $70 \%$ студентов стали принимать активное участие в учебном процессе на постоянной основе. Это довольно существенный результат. В данном пространстве обучающиеся вынуждены были самостоятельно готовиться по каждому элементу изучаемой темы, выполнять все задания в определенные временные промежутки (дедлайны), отвечать на все вопросы, не имея возможности подсмотреть какую-либо информацию у соседа по парте, причем все действия присутствующих на образовательной платформе формируются как цифровые следы и фиксируются. Таким образом, отсутствует вероятность пропуска педагогом информации, потери ответов или преобразования их в спам. Еще одной положительной особенностью является тот факт, что структура любого занятия, как и всё взаимодействие между субъектами образовательного процесса, становится прозрачным не только для педагогов и обучающихся, но и для руководства образовательной организации. Наличие данного фактора резко увеличивает необходимость формирования высокого качественного уровня размещаемых образовательных элементов с обеих сторон процесса.

Приведем некоторые примеры использования цифровых технологий в процессе обучения.

Во-первых, вместо банальной переклички современные педагоги практикуют инструмент Menti, используя который, возможно моментально сбросить студентам ссылку и код, с их помощью сформируют персонализацию субъектов, присутствующих в данный момент на паре, тем самым произведя экономию времени. С помощью данного инструмента можно также задавать любые вопросы в течение всего занятия и фиксировать ответы всех студентов одновременно, определять индивидуально потраченное студентами время на ответ, если существует такая необходимость.

Во-вторых, для реализации командной работы используются такие инструменты, как Miro, Trello, Google Docs и Sutori.

Miro (ранее RealtimeBoard) - это интерактивная платформа для совместной работы в режиме онлайн, сервис для создания ментальных карт. Miro позволяет распредёленным группам эффективно работать вместе: от мозгового штурма с помощью цифровых заметок до планирования и управления гибкими рабочими процессами. На платформе вы можете распределить свой проект на блоки и разграничить зоны ответственности указать, кто и за что отвечает. С помощью данного инструмента есть возможность создавать доски для командной работы, крепить на эти доски одновременно членами команды разноразмерные, разноцветные стикеры, заполнять их текстом, отмечать авторство, соединять их на основании зависимости или других факторов и т.д.

Trello - это одна из самых популярных систем управления проектами в режиме онлайн. Она позволяет эффективно организовывать групповую работу по японской методологии канбан-досок. Трелло состоит из четырёх вложенных компонентов: команды, собирающие в себе доски, которые разделены на списки, состоящие из отдельных карточек. Доски могут быть публичными - открытыми, частично открытыми и закрытыми ограниченными командой и участниками. В карточки можно добавлять любую инфор- 
мацию, в том числе присоединяться как участнику и присоединять других.

Google Docs - это бесплатный офис, который всегда у вас под рукой со всеми основными функциями. Имеется цифровой бот для написания текста голосом, автоматическое сохранение документа даже без названия и со всеми версиями правок, можно организовывать дискуссии, привязанные к отрывкам вашего текста. Также большую пользу может принести формирование обратной связи с помощью Google-формы для опроса или голосования.

Вести конспект можно электронно и совместно с помощью инструмента Sutori, который является бесплатным онлайн сервисом. Здесь возможно быстро создавать интерактивный материал с картинками, ссылками, опросами и др.

Каждое учебное занятие может начинаться с определения и фиксирования цели, сопровождаться цифровыми образовательными инструментами в процессе проведения образовательного мероприятия и заканчиваться электронной обратной связью в виде ответов на вопросы по пройденному материалу, электронных тестов, ограниченных по времени, и раскрытием эмоционального состояния студентов и отношения их к элементам проведенного мероприятия.

Основные трудности, возникающие при наложении онлайн и офлайн образовательных сред друг на друга. При соединении двух образовательных сред, контактной и цифровой одновременно, придется столкнуться с рядом трудностей [4]:

- образовательные мероприятия необходимо тщательно организовывать, продумывать все элементы, в том числе обратную связь, практически поминутно $[5,6]$;

- необходима постоянная аналитическая деятельность в области данных (цифровых следов);

- необходимо реализовывать проектную деятельность обучающихся и образовательного процесса, выстраивать индивидуальный вектор развития [7], то есть заниматься датамоделированием;

- необходимо внедрение в образовательный процесс педагогического дизайна выстраивания процесса обучения таким об- разом, чтобы у студентов была групповая работа, творческие проекты и большой обмен опытом, а учебные материалы разработаны так, чтобы они были понятны и хорошо запоминались, возможно введение элементов игрового обучения - геймификации.

Университет НТИ «20.35» первым разработал образовательные интенсивы в области новейшей профессии - дата-инженер в образовании. Этот специалист собирает данные об учебном опыте, так называемые цифровые следы, которые позволяют анализировать развитие обучающихся, выстраивать и корректировать индивидуальную образовательную траекторию обучения с использованием педагогического дизайна, формировать мотиваторы, удерживающие внимание обучающихся, поддерживать эмоциональную вовлеченность субъектов в образовательный процесс $[7,8]$.

Регулярный сбор цифровых следов студентов и проведение взаимосвязи с освоением компетенций позволит в процессе получения высшего образования сформировать цифровой профиль каждого студента - наглядный образ сформированного набора знаний, умений и навыков в рамках полученной профессии.

Заключение. Внедрение новейших цифровых технологий в образовательный процесс несет за собой появление огромного количества положительных особенностей, оказывающих влияние в первую очередь на резкий рост интенсивности обучения и вовлеченности студентов в образовательный процесс, что, как следствие, повышает уровень освоенности преподаваемого материала. Также объективируется оценочная система уровня знаний, умений и навыков, что позволит с помощью измеримых элементов оценивать сформированность компетенций, которыми овладевают студенты в процессе обучения. Отрицательные особенности имеют отношение к неэффективной технической организации цифрового пространства, отсутствию непрерывного Интернет-соединения и пользовательского опыта.

\section{Литература}

1. Гудкова С.А., Руденко А.Н. Требования современного рынка труда к выпускни- 
кам вузов. В сборнике: Модернизация экономики России: отраслевой и региональный аспект. Материалы международной научнопрактической конференции профессорскопреподавательского состава, молодых ученых и студентов. - 2019. - С. 405-408.

2. Руденко А.Н. Методологические основания изучения внутренних факторов интеллектуального потенциала студенчества Ростовской области // Гуманитарий Юга России. - 2018. - Т. 7. - №1. - С. 201-209.

3. Гафиатулина Н.Х., Касьянов В. В., Самызин П. С., Самызин С. И. Российское общество в условиях самоизоляции. Социальные эффекты и последствия пандемии covid-19. Монография. - Москва, 2020.

4. Гафиатулина Н.Х., Вакулюк А.А., Федоренко Э. Э. Информационно-коммуникационные технологии и их роль в прогнозировании социальных конфликтов // Национальное здоровье. - 2016. - №3-4.

5. Гафиатулина Н.Х., Рачипа А.В., Самысин С.И. Информационная сетевая среда как фактор влияния на социальное здоровье российской студенческой молодежи // Гуманитарные, социально-экономические и общественные науки. - 2018. - №1. - С.23-27.

6. Gafiatulina N. Kh., Imgrunt S.I., Samygin S.I. Social security and social health of Russian society: monograph. - Saarbucken: Lap Lambert Academic Publishing RU, 2017. — 124 p.

7. Руденко А.Н. Интеллектуальный потенциал студенчества региональных вузов. В сборнике: Модернизация экономики России: отраслевой и региональный аспект. Материалы международной научно-практической конференции профессорско-преподавательского состава, молодых ученых и студентов. - 2018. - С. 352-356.

8. EduNet: знания - в каждый мозг. Л. Малышева, Н. Киясов, Е. Кулешова. [Электорнный ресурс]. - Режим доступа: https:// ntinews.ru/in_progress/likbez/edunet-znaniyav-kazhdyy-mozg.html.

\section{References}

1. Gudkova S.A., Rudenko A.N. Trebovanija sovremennogo rynka truda $\mathrm{k}$ vypusknikam vuzov. V sbornike: Modernizacija jekonomiki Rossii: otraslevoj i regional'nyj aspekt. Materialy mezhdunarodnoj nauchno-prakticheskoj konferencii professorsko-prepodavatel'skogo sostava, molodyh uchenyh i studentov [Requirements of the modern labor market for University graduates. In the collection: Modernization of the Russian economy: industry and regional aspects. Materials of the international scientific and practical conference of teaching staff, young scientists and students]. 2019. - Pp. 405-408.

2. Rudenko A.N. Metodologicheskie osnovanija izuchenija vnutrennih faktorov intellektual'nogo potenciala studenchestva Rostovskoj oblasti [Methodological bases for studying internal factors of intellectual potential of students in the Rostov region] // Gumanitarij Juga Rossii [Humanities of the South of Russia]. - 2018. - Vol. 7. — №1. - Pp. 201-209.

3. Gafiatulina N.H., Kas'janov V. V., Samygin P.S., Samygin S.I. Rossijskoe obshhestvo v uslovijah samoizoljacii. Social'nye jeffekty i posledstvija pandemii covid-19. Monografija [Russian society in conditions of self-isolation. Social effects and consequences of the covid-19 pandemic. Monograph]. - Moscow, 2020.

4. Gafiatulina N.H., VakuljukA.A., Fedorenko Je. Je. Informacionno-kommunikacionnye tehnologii i ih rol' $\mathrm{v}$ prognozirovanii social'nyh konfliktov [Information and communication technologies and their role in predicting social conflicts] // Nacional'noe zdorov'e [National health]. - 2016. - №3-4.

5. Gafiatulina N.H., RachipaA.V., Samygin S. I. Informacionnaja setevaja sreda kak faktor vlijanija na social'noe zdorov'e rossijskoj studencheskoj molodezhi [Information network environment as a factor of influence on the social health of Russian students] // Gumanitarnye, social'no-jekonomicheskie i obshhestvennye nauki [Humanities, socio-economic and social Sciences]. - 2018. - №1. - Pp. 23-27.

6. Gafiatulina N. Kh., Imgrunt S.I., Samygin S. I. Social security and social health of Russian society: monograph. - Saarbucken: Lap Lambert Academic Publishing RU, 2017. — 124 p.

7. Rudenko A.N. Intellektual'nyj potencial studenchestva regional'nyh vuzov. V sbornike: Modernizacija jekonomiki Rossii: otraslevoj i regional'nyj aspekt. Materialy mezhdunarodnoj nauchno-prakticheskoj konferencii professorsko-prepodavatel'skogo sostava, molodyh uchenyh i studentov [Intellectual potential of students of regional universities. In the collec- 
tion: Modernization of the Russian economy: industry and regional aspect. Materials of the international scientific and practical conference of teaching staff, young scientists and students]. 2018. - Pp. 352-356.
8. EduNet: znanija — v kazhdyj mozg [EduNet: knowledge - in every brain]. L. Malysheva, N. Kijasov, E. Kuleshova. [Jelektornnyj resurs]. — URL: https://ntinews.ru/in_progress/ likbez/edunet-znaniya-v-kazhdyy-mozg.html.

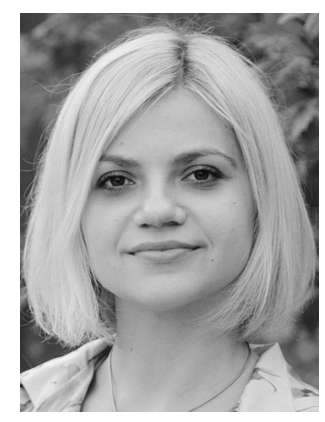

Руденко Анна Николаевна - кандидат социологических наук, доцент кафедры «Управление персоналом и социология» Ростовского государственного экономического университета (РИНХ).

Rudenko Anna Nikolaevna - Candidate of Sociological Sciences, Associate Professor, Department of Personnel Management and Sociology, Rostov State University of Economics.

344082, г. Ростов-на-Дону, пер. Островского, 62, каб. 204 62 Ostrovsky ln., off. 204, 344082, Rostov-on-Don, Russia

E-mail: anya_rudenko@bk.ru 